\title{
Hydraulic Design and Optimization of a Modular Pump-turbine Runner
}

\author{
W. Schleicher ${ }^{\mathrm{a})}$ and A. Oztekin
}

Mechanical Engineering and Mechanics, P. C. Rossin School of Engineering and Applied Science, Lehigh University, Bethlehem, Pennsylvania 18015

\section{ABSTRACT}

A novel modular pumped-storage scheme is investigated that uses elevated water storage towers and cement pools as the upper and lower reservoirs. The scheme serves a second purpose as part of the wastewater treatment process, providing multiple benefits besides energy storage. A small pumped-storage scheme has been shown to be a competitive energy storage solution for micro renewable energy grids; however, pumpedstorage schemes have not been implemented on scales smaller than megawatts. Off-theshelf runner designs are not available for modular pumped-storage schemes, so a custom runner design is sought. A preliminary hydraulic design for a pump-turbine runner is examined and optimized for increased pumping hydraulic efficiency using a response surface optimization methodology. The hydraulic pumping efficiency was found to have improved by $1.06 \%$ at the best efficiency point, while turbine hydraulic efficiency decreased by $0.70 \%$ at the turbine best efficiency point. The round-trip efficiency for the system was estimated to be about $78 \%$, which is comparable to larger pumped-storage schemes currently in operation.

\section{KEYWORDS}

Modular Pumped-storage; Optimization; Turbulence; CFD

\footnotetext{
a) Corresponding Author: Electronic mail: wcs211@lehigh.edu Phone: +1-724-584-0143
} 


\section{INTRODUCTION}

Modern energy policies require power generation solutions with minimal environmental impact and carbon footprint. These policies favor renewable and sustainable energy sources such as wind, solar, nuclear, and hydro power; however, these energy sources have drawbacks. The demand for power changes throughout the day and is typically the lowest late at night and the highest in the late afternoon. Wind and solar energy are intermittent and prove difficult to schedule power output to the grid. Nuclear plants cannot quickly meet energy demands when sudden changes in consumption occur. These drawbacks lead to the need to store energy when there is excess power production and consume the stored energy at peak demand times.

Two technologies are commonly implemented for utility level energy storage: pumped-hydro energy storage (PHES) and compressed air energy storage (CAES). These technologies have been proven as effective large-scale energy storage means; however, they are rarely implemented at a small system level. Batteries, flywheels, and ultra-capacitors are more common for these small systems, but there are minimal options for storing moderate amounts of energy [1, 2]. Micro-hydro, a subset of small hydro, encompasses units that produce up to $100 \mathrm{~kW}$ of power and covers this middle ground of power storage solutions. A pumped-storage scheme can be implemented to fulfill the need for energy storage for this range of power.

PHES has a well-established history in the United States, with the oldest facility dating back to 1929. Development of pumped storage schemes did not make much progress until the 1960's when nuclear power facilities became operational. Pump storage schemes were seen as an important compliment to nuclear power because of nuclear power's inability to quickly change power production. Development of pumped-storage slowed in the 1980s with the decline of the use of nuclear power. In the 1990s, the United States began restructuring the power sector by 
transitioning to wholesale generation and transmission markets. This transition to wholesale generation markets left many investment uncertainties in pumped-storage since these schemes are net consumers of energy. It was not until 2007 that the Federal Energy Regulatory Commission (FERC) issued Order 890, which required energy storage solutions to be evaluated at the same level as pure generation solutions [3].

Pumped-storage schemes are a growing interdisciplinary research field, and will continue growing as more renewable energy generation sources are integrated into power grids. Sivakumar et al. [4] studied the impact of pumped-storage schemes in India and concluded operating these schemes is beneficial in meeting peak energy demands and the energy cost is less than gas and diesel power plants when providing peak generation. Ma et al. [5] investigated the feasibility of PHES and battery storage for a renewable energy power island. They concluded that a PHES scheme would be cost completive as an energy storage solution. They also recognized that an off-the-shelf micro pump-turbine solution is not available and suggest studying a micro-pump-turbine unit as worthy future research. This manuscript investigates such a micro-pump-turbine unit.

Variable-speed pump-turbines are a popular topic in pumped-storage because of their advantages over fixed-speed units such as improved efficiency and reactive power control. Anagnostopoulos and Papantonis [6] designed a pumping station for a wind and hydro pumpedstorage power plant. They used an evolutionary optimization algorithm to determine the pump configuration with the highest possible energy storage rate for the lowest possible investment cost, and concluded a variable-speed pump was the most advantageous configuration. Wang and Jiang [7] researched a multilevel cascaded H-bridge static frequency converter in a pump-turbine startup synchronous motor. They concluded that it was more compact, had a fast response speed, 
high control precision, and low current harmonic distortion compared to conventional static frequency converters. Sivakumar et al. [8] studied adding variable-speed induction generators to the Kadamparai pumped-storage plant modernization project, and recommend choosing variablespeed technology for its improved efficiency and better grid frequency control.

Pumped-storage schemes have not successfully been implemented on a scale less than hundreds of megawatts; however, the idea of modular pumped-storage aims to bring the technology to this scale. Modular pumped-storage has been a concept since the early 1990s, but there has been little progress to advance this idea over the past few decades $[9,10]$. With the previously mentioned renewable energy sources playing a more dominate role in the generation market, modular pumped-storage is slowly gaining more attention for research. This storage scheme uses a closed loop system of tanks at different elevations with pump-turbines that are designed for various generic conditions. This reduces the price per kilowatt significantly compared to the larger units currently used, reduces the space required for pumped-storage schemes, and minimizes the environmental impacts on rivers and lakes [11]. The original proposed concept called for units ranging from 100 to $200 \mathrm{MW}$ compared to planned projects of $1000 \mathrm{MW}$ at the time. Micro-hydro pumped-storage schemes involve even less power than this.

One challenge to the incorporation of a $100 \mathrm{~kW}$ pumped-storage scheme is the cost effectiveness compared to other means of energy storage such as lead-acid batteries. Factors involved in comparing these energy schemes include their efficiency, engineering costs, capital costs, installation costs, cycle life, size, operating environments, safety, and maintenance of the system. For a micro pumped-storage scheme to be competitive, they must either serve more purposes than just energy storage and regulation or be a necessity in remote regions. One such way could be to incorporate a pumped-storage scheme into a water treatment facility. The 
pumped-storage scheme would provide the added benefit of improving the quality of the wastewater by aerating during pumping operation, thus becoming part of the wastewater treatment. Pumped-storage schemes would also be ideal for remote locations such as regions of Alaska. In these remote locations, power is vital for survival and many regions do not have their own power grid. When power fails in these regions, lives are put at risk and can lead to a need to evacuate an entire town. A pumped-storage scheme would benefit these remote regions and improve their quality of life. Both of these implementations would be closed-loop and avoid environmental damages to aquatic ecosystems and life.

A novel design is required for these micro pumped-storage schemes. Nautiyal et al. [12] showed that standard pump models could be used as turbines for micro-hydro power generation; however, the difference between the best turbine and pump efficiencies was as much as $8.5 \%$. For energy storage purposes, the goal is to minimize the difference in best efficiency between pump and turbine operation. While the system could have a dedicated pump and turbine, it would greatly increase the overall cost. The best solution is a custom design system with a runner that works in both the pump and turbine directions.

In section two of this manuscript, the optimization method is introduced. In section three, the modular PHES scheme concept is proposed. The design operating conditions are then determined. A preliminary hydraulic turbine design is derived based on existing methods well documented in the literature. The computational methodology is discussed in detail. In section four, the findings from the numerical studies are presented. A mesh discretization study is performed to verify the dependence of power and head on cell size. The preliminary runner design was characterized for its predicted operating range in pump and turbine directions. The runner is optimized at its pump best efficiency design condition using a response surface 
optimization methodology. The optimized runner is characterized in pump and turbine directions and compared. The flow fields in pump and turbine directions at the runner's midspan is compared between the preliminary and optimized design. Section five concludes this manuscript.

\section{OPTIMIZATION METHOD}

Optimization strategies are vital to the design process. The simplest approach to optimization is to change one of the design variables at a time while holding other design variables constant. This method is highly inefficient and rarely arrives near an optimized design [13]. It is better to approach optimization from a more systematic perspective. This usually entails determining any objective functions, or goals, for the optimization, whether the aim is to minimize or maximize the objective function, any constraints the objective functions must obey, and the bounds on the investigated design space. The objective functions can be linear or non-linear, implicit or explicit functions. Design variables can be continuous or discrete. The choice of optimization technique will ultimately depend on these factors. Optimization algorithms can be divided into two basic groups: local or global [14].

Local optimization methods use gradients to search for local optimum conditions. These methods generally operate in two steps. In the first step, the algorithm determines the output of the objective function around the starting design point. It then estimates the gradients and determines the best direction to move the design variables. In the second step, the design variables are changed to move in the direction determined in step one until no further progress can be made. Examples of local optimization include Newton's method, variable metric methods, Sequential Unconstrained Minimization Techniques (SUMT), and direct or constrained methods [14]. These methods excel when there are more than approximately 50 design 
variables; however, they are only capable of finding local extrema and are dependent on the initial design variables.

Many optimization problems have multiple extrema, making it difficult to arrive at the true global minima or maxima using local optimization techniques. One way to circumvent this problem is to use multiple starting points for the local optimization method; however, using a global optimization method may be better suited for this task. Global optimization methods have a better chance of finding the true global optimum. Global optimization algorithms are typically used when the number of design variables is less than 50. Computationally speaking, global optimization algorithms are more expensive compared to local optimization algorithms because the number of objective function evaluations increases rapidly with the number of design variables.

It is important to select an optimization strategy considering the output responses and optimization constraints. For example, a local optimization algorithm is inappropriate for output responses that have many local extrema, or a global algorithm may be too intensive if the output responses are linear. A global optimization method was chosen for the pump-turbine system because of the non-linear nature of hydraulic efficiency with respect to the chosen design variables. An adaptive response surface methodology, a global optimization algorithm, was implemented for this reason.

A response surface optimization methodology is a form of a function approximation optimization that uses an experimental design combined with a regression model to approximate the behavior of a system. This optimization method was first pioneered in the 1950s by Box and Wilson [15]. The optimization methodology has gained popularity in recent years and has been applied to turbomachinery design problems. Jang et al. [16] applied this method to optimization 
of a single stage axial compressor and Kim et al. [17] used this methodology on a centrifugal compressor. Li et al. [18], Rubechini et al. [19], and Cravero and Macelloni [20] optimized multistage turbines with a response surface methodology. Schleicher et al. [21] have also successfully applied this method to optimizing a portable hydrokinetic turbine and continue to be active in developing small, hydropower turbomachines [22, 23, 24, 25].

The first step in the response surface optimization scheme is to define the goals of the optimization. These design goals could be to minimize power input in pumping operation and maximize power output in turbine operation. Once the goals of the optimization are set, the geometric parameters for the system must be selected. The next step is to define the limits on the design space to be studied. This can be difficult to do on the first design iteration because the global minima or maxima may not actually be in that range. Therefore, for the first design iteration it is suggested that the design space be as large as possible. If at the end of the first design iteration the design goals are met on the edge of the design space for any variable, the design space should be adjusted further in that direction in an attempt to bring the maxima or minima into the design space.

An appropriate experimental design is then selected such as a central composite design, optimal space-filling design, or any of their variants. In this manuscript, a central composite design was used. The simulations are then solved and post-processed for performance characteristics relevant to the optimization goals. These results are regressed, and an optimal solution is sought from the regression. A non-parametric regression, a Support Vector Method type technique, was implemented to regress the simulations. A non-iterative screening method based on the Hammersley algorithm was applied to the regression. Pareto fronts were generated from the screened regressions. The decision support system that determined optimum conditions 
from the Pareto fronts used a weighted aggregate method. The regression is further refined with more simulations until the parameterized geometric model has converged on an optimal solution within a given tolerance. More detail about the optimization methodology can be found in [21].

\section{DESIGN, MODELING, MESHING, AND NUMERICAL METHOD}

Pictured in FIG. 1 is an example of how this closed-loop pumped-storage scheme may look like. An elevated water storage tower is used as the scheme's upper reservoir while the lower reservoir is comprised of a cement pool. The water tower's feet are anchored to the bottom of the pool, and a cement equipment room is placed at the center of this pool, directly under the water tower's penstock. The pump-turbine is located within this equipment room. This design allows for proper placement of the runner to avoid cavitation in the expected operating conditions.

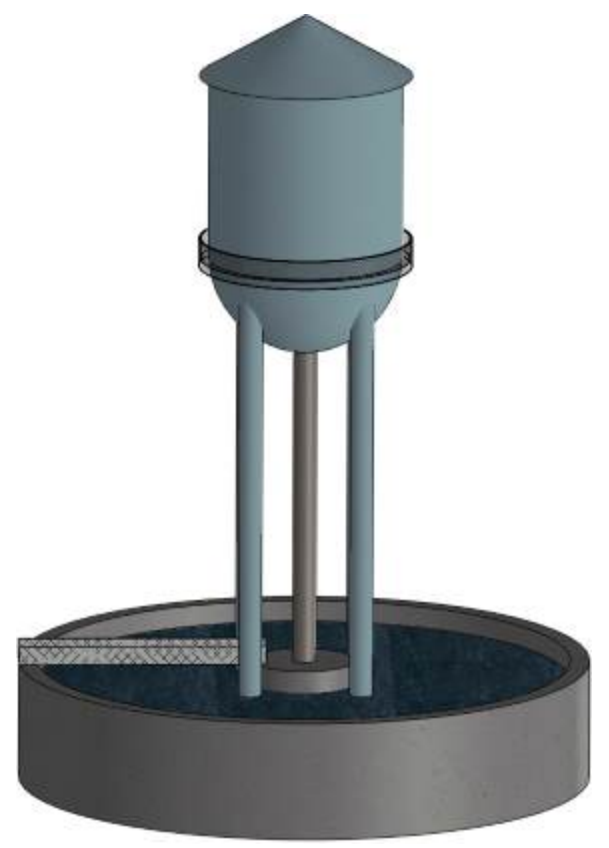

FIG. 1. Overview of the Proposed Pumped-storage Scheme

Designing the pump-turbine starts with determining the head, flow rate, power consumption, and efficiency for the unit in the pump direction. A micro-hydro system could utilize an elevated water storage tank as the upper reservoir. If the tower is approximately ten stories tall, the design 
head should be approximately $33 \mathrm{~m}$. Flow rate is estimated based on the volume of water to be stored and the time required to fill the upper reservoir. A flow rate of $0.2 \mathrm{~m}^{3} / \mathrm{s}$ could deliver 750,000 gallons of water over a 4 hour period during off-peak production hours. An achievable hydraulic efficiency for the pump would be around $92 \%$, similar to larger units in existence. Using these three design parameters, the pump would require $65.725 \mathrm{~kW}$ input power to the shaft.

The selected design parameters are then used to predict some basic geometric parameters for a preliminary design. The U.S. Bureau of Reclamation studied existing pump-turbine designs and characterized basic design features as a function of pump specific speed [26]. Estimating a rotation rate of $125.6 \mathrm{rad} / \mathrm{s}$, the pump's specific speed $\left(\eta_{s p}\right.$, where $N$ is the rotation rate in $\mathrm{rad} / \mathrm{s}$, $Q$ is the flow rate, and $H$ is the head) is determined to be 0.74 , resulting in an impeller diameter of $411.2 \mathrm{~mm}$, eye diameter of $243.3 \mathrm{~mm}$, and impeller discharge height of $39.6 \mathrm{~mm}$. Note that the U.S. Bureau of Reclamation document [26] uses the less strict form of specific speed where $N$ is in rotations per minute and the $g$ term is excluded; however, for consistency the strict, dimensionless form is presented in this manuscript.

$$
\eta_{s p}=\frac{N Q^{0.5}}{(g H)^{0.75}} \quad C_{m}=K_{C m} \sqrt{2 g H} \quad \beta=\sin ^{-1} \frac{Z s b}{\pi D b-Q / C_{m}}
$$

Next the meridional absolute velocity coefficients are determined using the relationship with specific speed as originally proposed by Stepanoff and adapted by Round [27]. These coefficients for the inflow and outflow are 0.14 and 0.17 , respectively. The meridional absolute velocities themselves ( $C_{m}$, where $K_{C m}$ is an empirical coefficient) are determined through equation (1) to be $3.47 \mathrm{~m} / \mathrm{s}$ and $4.20 \mathrm{~m} / \mathrm{s}$, respectively. The relative blade angles to the flow can be determined through equation (1), where $Z$ is the number of blades, $s$ is the thickness of each blade, $D$ is the diameter at the inlet or outlet, and $b$ is the length between the hub and shroud at 
the location of interest [28]. At the trailing edge of the blade in pump operation, the diameters are assumed to be the same at the hub and shroud. If six blades have a thickness of $25 \mathrm{~mm}$ each, the blade angle is $15.3^{\circ}$ relative to the tangential. At the hub and shroud of the inflow, the relative blade angles are $76.5^{\circ}$ and $34.8^{\circ}$, respectively. A linear variation in relative blade angle is usually assumed in a preliminary design between the leading edge and trailing edge. The preliminary design based on these parameters is depicted in FIG. 2 .

Pictured in FIG. 3B is an overview of the computational domain mesh. The domain is composed of two regions: the runner and draft tube regions. The runner region is modeled by a single blade passage with rotational periodic boundary conditions. FIG. 3A depicts the turbine blade surface mesh. Special attention was paid to resolve the boundary layers adequately for the implemented turbulence model.
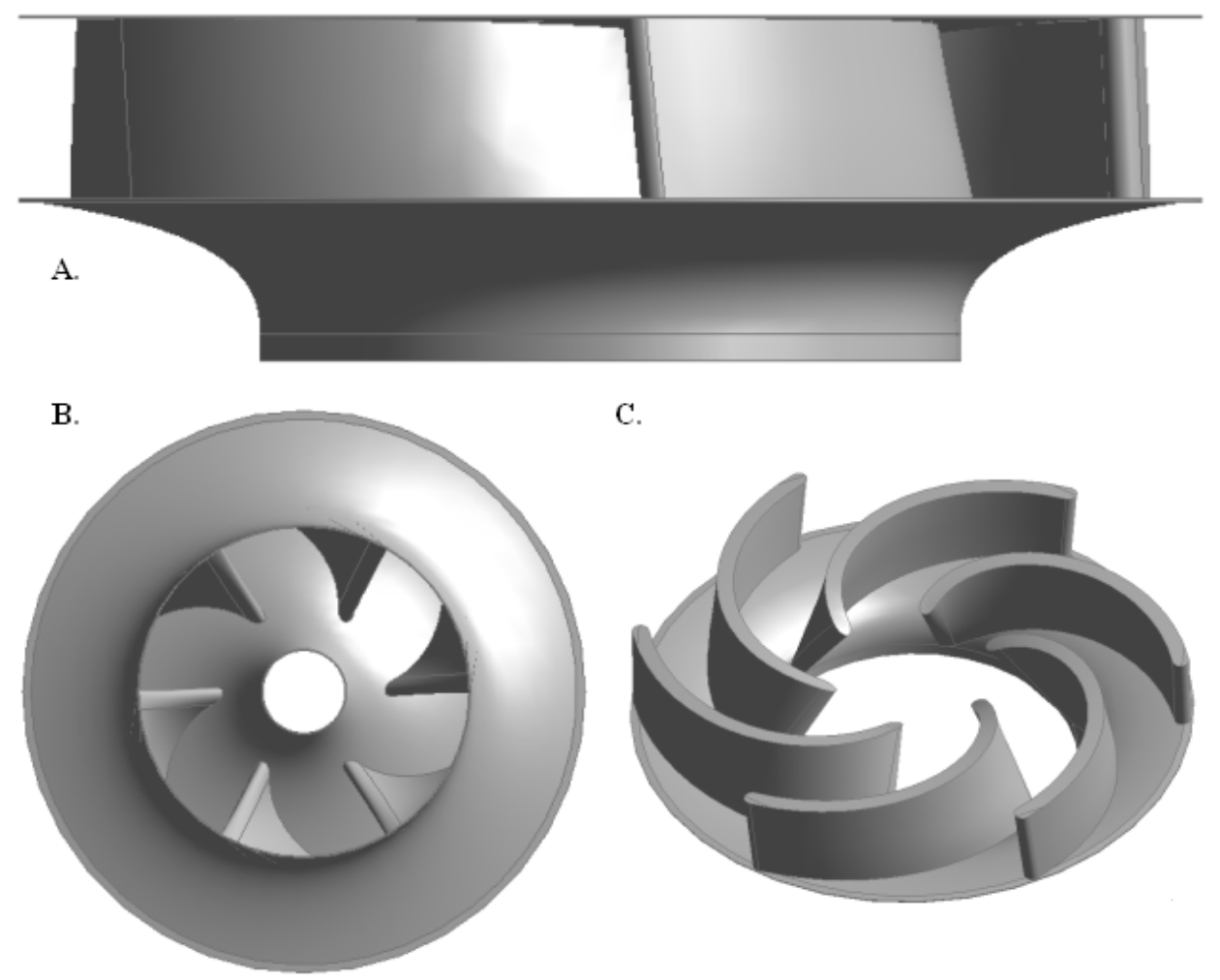

C.

FIG. 2. Preliminary Hydraulic Design of the Pump-turbine Runner 
A.

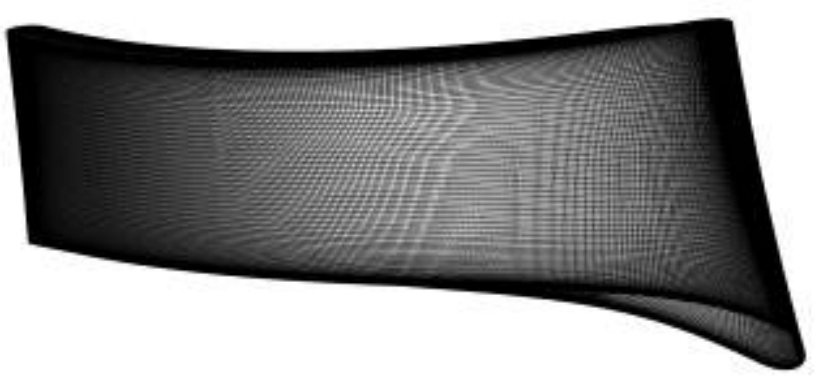

B.

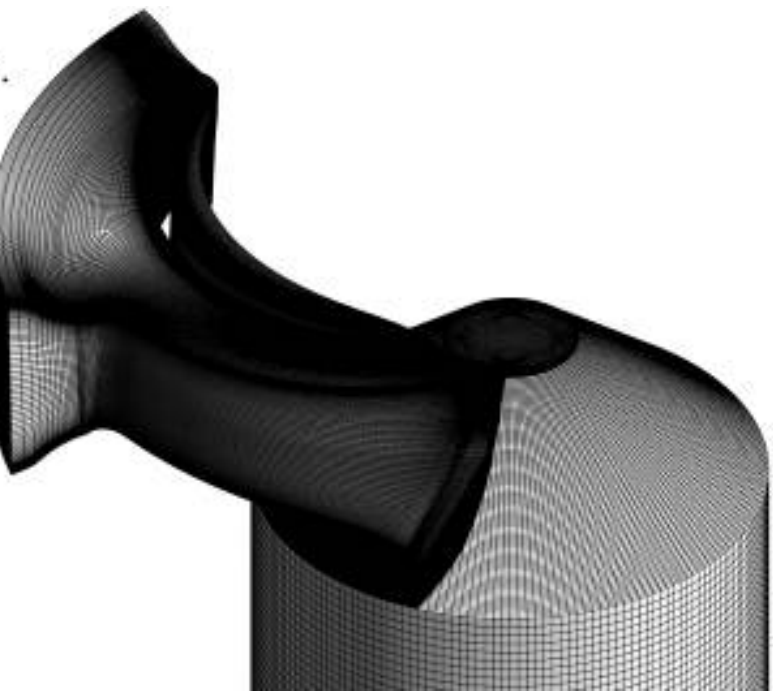

FIG. 3. A. Blade Mesh B. Overview of the Domain Mesh

The computations were carried out with ANSYS CFX using the steady-state solver method with multiple frames of reference and a mixing plane between the two mesh regions. The rotating reference frame used in the vicinity of the turbine allows the flow field to be solved in a steady non-inertial reference frame by including centrifugal and Coriolis force source terms into the transport equations.

Turbulence was modeled with Menter's k- $\omega$ SST $[29,30]$ two-equation eddy-viscosity model, which improves the prediction of adverse pressure gradients in the near wall region compared to the standard k- $\omega$ and k- $\varepsilon$ models. The equations for kinematic eddy viscosity, turbulent kinetic energy, and specific dissipation rate are shown in equation (2).

$$
\begin{gathered}
v_{T}=\frac{\alpha_{1} k}{\max \left(\alpha_{1} \omega, S F_{2}\right)} \\
\frac{\partial k}{\partial t}+U_{j} \frac{\partial k}{\partial x_{j}}=\tau_{i j} \frac{\partial U_{i}}{\partial x_{j}}-\beta^{*} k \omega+\frac{\partial}{\partial x_{j}}\left[\left(v+\sigma_{k} v_{T}\right) \frac{\partial k}{\partial x_{j}}\right] \\
\frac{\partial \omega}{\partial t}+U_{j} \frac{\partial \omega}{\partial x_{j}}=\alpha S^{2}-\beta \omega^{2}+\frac{\partial}{\partial x_{j}}\left[\left(v+\sigma_{\omega} v_{T}\right) \frac{\partial \omega}{\partial x_{j}}\right]+2\left(1-F_{1}\right) \sigma_{\omega 2} \frac{1}{\omega} \frac{\partial k}{\partial x_{i}} \frac{\partial \omega}{\partial x_{i}}
\end{gathered}
$$


Here, $v_{T}$ is the turbulent viscosity, $v$ is the kinematic viscosity, $k$ is the turbulent kinetic energy, $\omega$ is the specific dissipation rate, $\alpha_{1}$ is a closure coefficient, $U$ is the velocity, and $S$ is the mean rate-of-strain tensor. The blending functions $F_{1}$ and $F_{2}$ are not shown, but the implemented model uses the original implementation of the k- $\omega$ SST turbulence model.

On the inlet of the computational domain, a fixed mass flow rate was assumed as well as a zero gradient condition for the pressure equation. A turbulent intensity of approximately $5 \%$ and a turbulent mixing length of $\mathrm{L}=0.07 D_{H}$, where $D_{H}$ is the hydraulic diameter of the inlet, was assumed. On the outlet, a zero gradient condition for velocity, turbulent kinetic energy, and specific dissipation rate was imposed as well as a fixed gauge pressure. The solid boundaries were modeled as no-slip, hydraulically smooth walls that moved at the same speed as the local reference frame. Wall functions were employed to link the turbulent quantities to the no-slip walls. The runner and draft tube mesh regions were linked together through the Generalized Grid Interface algorithm with a mixing plane that circumferentially averaged the total pressure from one region and applied it as the boundary condition for the next region. A single blade passage was modeled with rotational periodic boundary conditions, reducing the cell number and computational resources needed to obtain a solution. The boundary conditions are depicted in the schematic, see FIG. 4. 


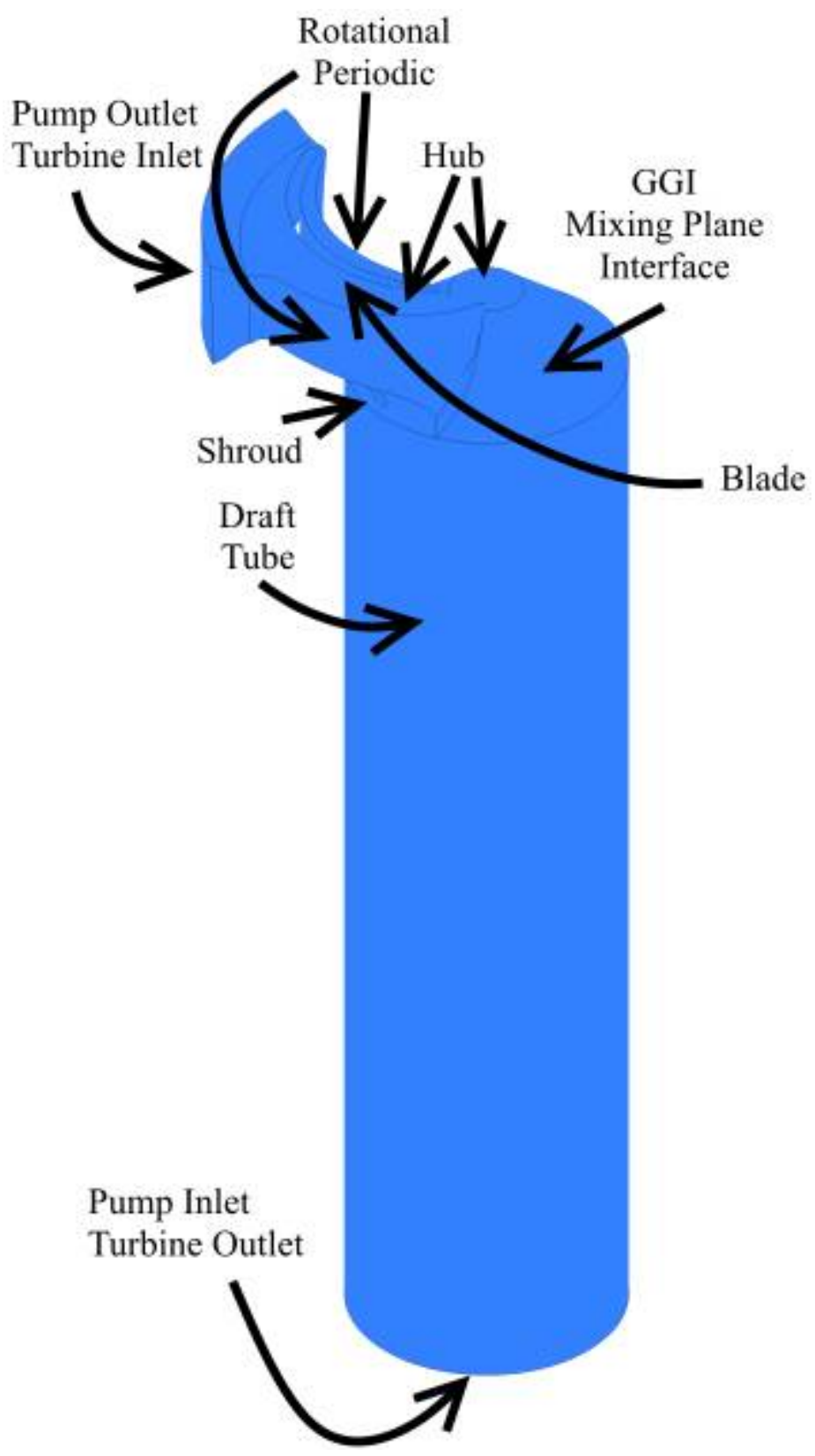

FIG. 4. Boundary Conditions for the Numerical Study

\section{RESULTS AND DISCUSSION}

Displayed in FIG. 5 are results from a mesh discretization study in turbine operation. The runner was simulated at a volumetric flow rate of $0.2 \mathrm{~m}^{3} / \mathrm{s}, 125.6 \mathrm{rad} / \mathrm{s}$, and a 6 degree flow angle relative to the circumferential direction. The number of cells was varied from approximately 0.1 
to 9 million. FIG. 5A depicts results for output mechanical power while FIG. 5B depicts the turbine's calculated head differential. The results show that a nine million cell mesh reaches the
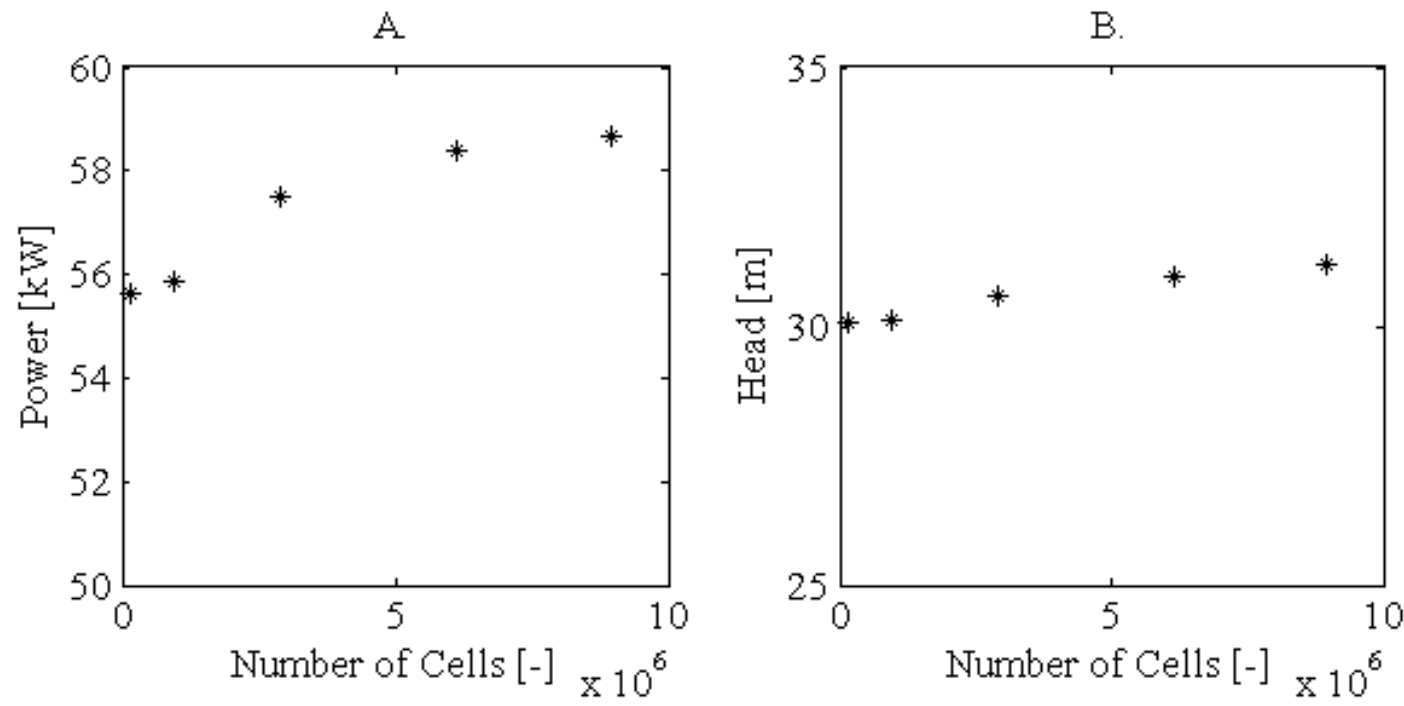

FIG. 5. Discretization Study Plots for A. Power and B. Head in Turbine Operation asymptotic range for mesh independence for both power and head. There is a $0.51 \%$ relative error for power and $0.66 \%$ relative error for head between the nine million cell mesh and the previous coarser mesh ( 6 million).

The preliminary runner design was characterized for its expected operating range in both pump and turbine operation. Volumetric flow rate and flow angle were varied with a constant $125.6 \mathrm{rad} / \mathrm{s}$ rotation rate (rotation direction changes based on pump and turbine operation). These performance results are presented later in this manuscript alongside its optimized performance characteristics.

The runner design was optimized at its designed best efficiency point in pump operation ( $Q=0.2 \mathrm{~m}^{3} / \mathrm{s}, H=33 \mathrm{~m}, 6^{\circ}$ flow angle). The goal was to maximize the runner's hydraulic efficiency at this operating condition. An adaptive response surface methodology was employed for the optimization. The geometric parameters used in the optimization are listed in TABLE 1 and depicted in FIG. 6. The design space investigated in the optimization is shown in TABLE 2. 
A central composite design of experiments with an embedded fractional factorial experiment of resolution $\mathrm{V}$ consisting of 27 simulations was used to populate the response surface.

\section{TABLE 1. Geometric Optimization Parameters}

\begin{tabular}{|ll|}
\hline Variable & Description \\
$\Delta B$ & Gate Height \\
$\Delta \theta_{H u b}$ & Blade Wrap Angle at the Hub \\
$\Delta \theta_{\text {Shroud }}$ & Blade Wrap Angle at the Shroud \\
$\theta_{L E}$ & Leading Edge Lean Angle \\
$\theta_{T E}$ & Trailing Edge Lean Angle \\
\hline
\end{tabular}

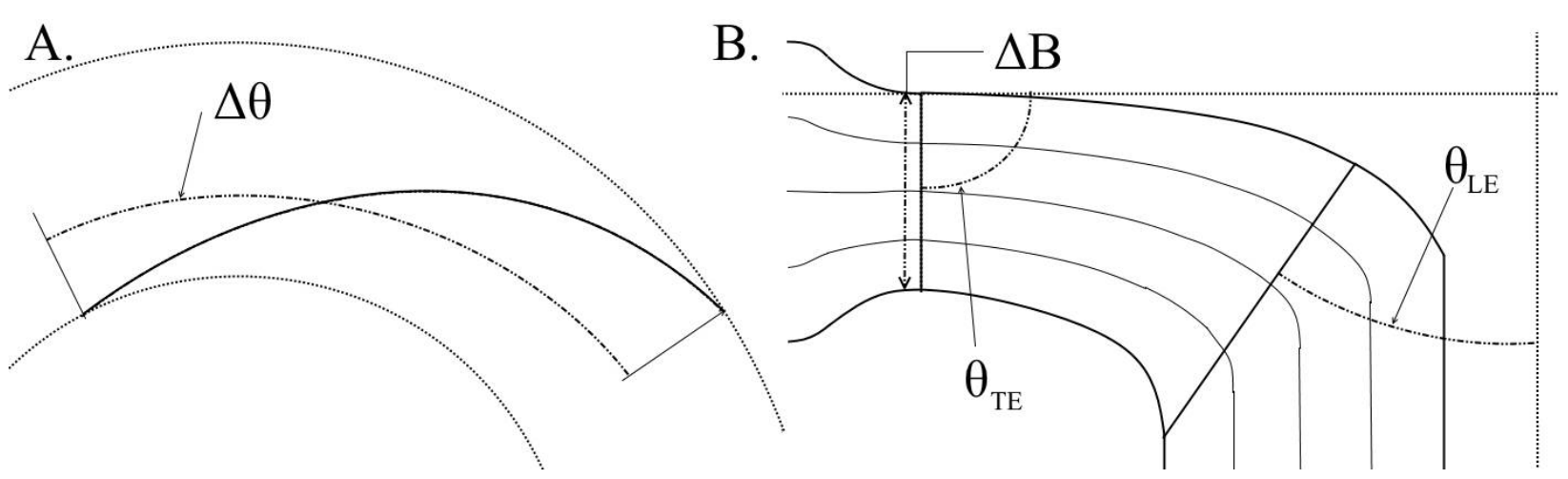

FIG. 6. A. Plan and B. Meridional View of the Runner with Optimization Variables 
TABLE 2. Design Space Investigated in the Optimization

\begin{tabular}{|lll|}
\hline Variable & Low Value & High Value \\
$\Delta B$ & $59.277 \mathrm{~mm}$ & $72.450 \mathrm{~mm}$ \\
$\Delta \theta_{H u b}$ & $68.832^{\circ}$ & $84.128^{\circ}$ \\
$\Delta \theta_{\text {Shroud }}$ & $31.349^{\circ}$ & $38.315^{\circ}$ \\
$\theta_{L E}$ & $31.671^{\circ}$ & $38.709^{\circ}$ \\
$\theta_{T E}$ & $81.000^{\circ}$ & $99.000^{\circ}$ \\
\hline
\end{tabular}

Plotted in FIG. 7 are various performance characteristics of both the preliminary and optimized runner geometries. The performance characteristics are displayed in unit quantities for comparison with other hydraulic turbomachinery designs. These definitions are depicted in equation (3).

$$
N_{11}=\frac{N D_{r e f}}{\sqrt{g H}} \quad Q_{11}=\frac{Q}{\sqrt{g H} D_{r e f}^{2}} \quad \eta_{H}=\frac{\tau \omega}{\rho g H Q}
$$

Here, $N$ is the roation rate in rad/s, $D_{\text {ref }}$ is the turbine's reference diameter of $411.2 \mathrm{~mm}, H$ is the head produced or required by the runner, $Q$ is the runner's discharge or volumetric flow rate, $\tau$ is the input or output torque to or from the runner, $\omega$ is the runner's rotation rate in $\mathrm{rad} / \mathrm{s}, \rho$ is the desity of water taken to be $997 \mathrm{~kg} / \mathrm{m}^{3}$, and $g$ is the local gravitational constant taken as 9.81 $\mathrm{m} / \mathrm{s}^{2}$.

FIG. 7A-C represent quantities in pump operation while FIG. 7D-F are for turbine operation. FIG. 7A represent the trend in unit power consumption versus unit flow. The slight shift upwards is indicative of less power consumption for the same operating head and flow conditions. A similar trend is seen in FIG. 7B for unit flow versus unit speed. The runner's hydraulic efficiency is plotted as a function of unit flow in FIG. 7C, and a slight improvement is seen in the runner's mid-range. The runner's pump hydraulic efficiency at its best efficiency point was improved by $1.06 \%$ from $96.3 \%$ to $97.4 \%$. The slight improvement in hydraulic efficiency is not as fruitful as would be desired; however, the preliminary design was a very 
good starting point for the hydraulic optimization. If the preliminary design was less efficient, the hydraulic optimization would have been more fruitful. This optimization method has been shown by the authors to greatly increase performance characteristics for hydrokinetic turbomachines [21, 31]

In turbine operation, the runner's hydraulic efficiency was slightly adversely affected. FIG. 7D plots the runner's hydraulic efficiency as a function of unit speed. At the low and high ends of the runner's unit speed, efficiency was slightly adversely affected in the optimized design; however, the efficiency was slightly improved in the runner's mid-range designed operating conditions. The hydraulic efficiency at its best efficiency point in turbine operation fell by $0.70 \%$ from $95.8 \%$ to $95.1 \%$. In FIG. $7 \mathrm{E}$ and F, the downward shift in values is due to an increase in the required head to operate the runner at the same swirl angle. This increase in required head is partially why the runner was on average less hydraulically efficient than the preliminary design. If the entire system's volumetric $\left(\eta_{V}\right)$ and mechanical $\left(\eta_{M}\right)$ efficiency are estimated to be $97 \%$ and $95 \%$, respectively, the total efficiency in pump $\left(\eta_{T, p}\right)$ and turbine $\left(\eta_{T, t}\right)$ operation as well as the round-trip $\left(\eta_{T}\right)$ efficiency of this system is estimated by 


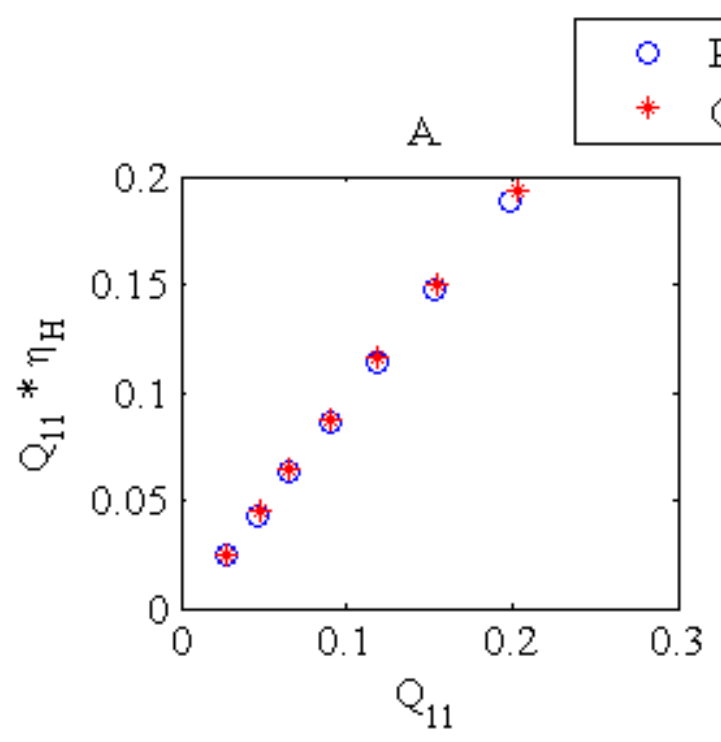

Preliminary
Optimized

B.
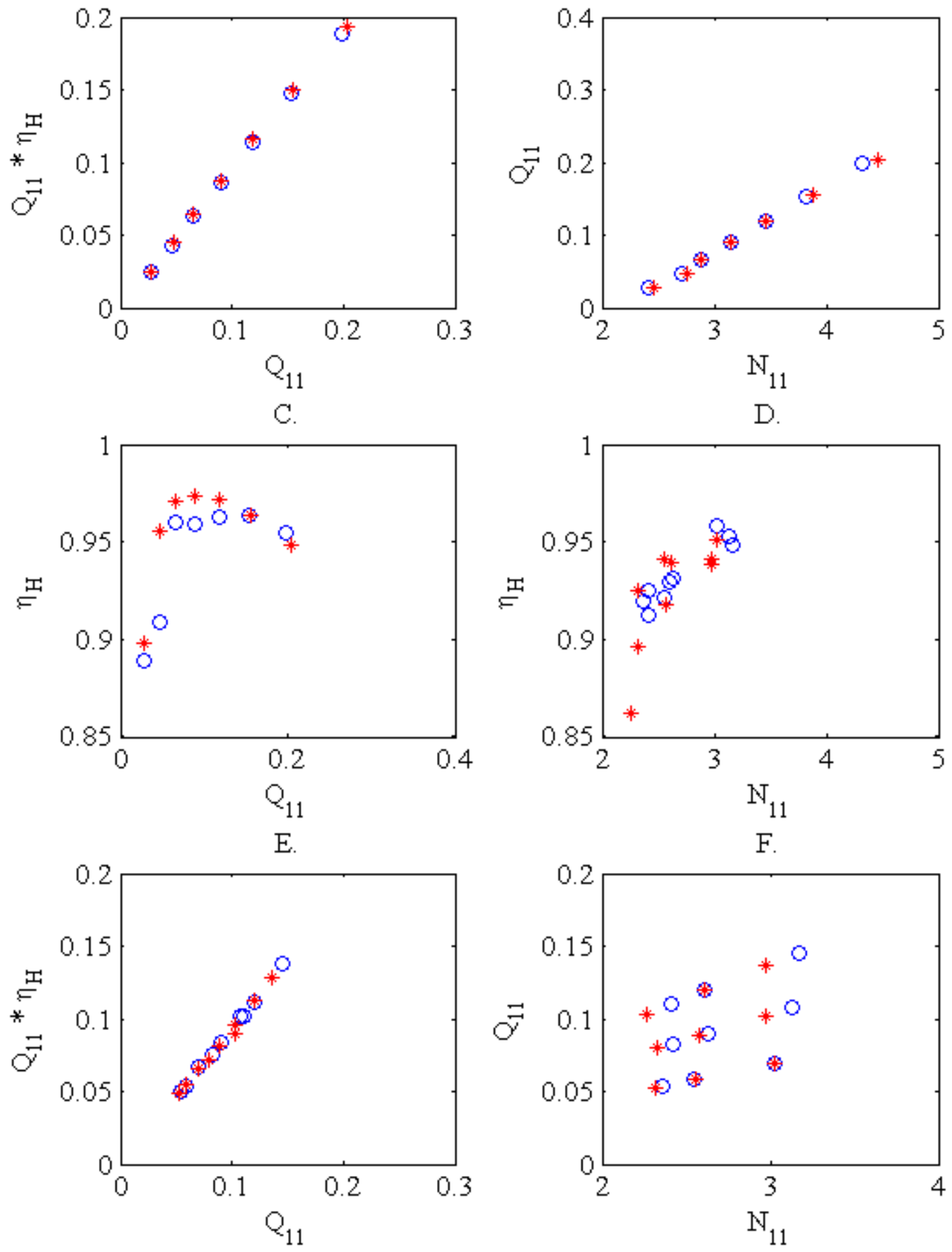

FIG. 7. Result Comparison between the Preliminary and Optimized Design 
equation (4). These total efficiencies are $89.8 \%$ for pump operation, $87.6 \%$ in turbine operation, and $78.7 \%$ round-trip.

$$
\eta_{T, p}=\eta_{V} \eta_{M} \eta_{H, p} \quad \eta_{T, t}=\eta_{V} \eta_{M} \eta_{H, t} \quad \eta_{T}=\eta_{T, p} \eta_{T, t}
$$

The preliminary pump-turbine design was an excellent starting point for the optimization process. The difference between the preliminary and optimized designs is small, and may even be negligible due to numerical uncertainty. Current implementations of pumped-storage schemes are on the order of 100 s of megawatts. If the hydraulic efficiency is improved by $1 \%$ in pump operation, this can amount to a few megawatts in power savings. Since this system is much smaller than these units, a $1 \%$ improvement in hydraulic efficiency is not as impactful. Also, the preliminary design methods have been used in practice for decades and may be fine-tuned to produce nearly optimum designs. A more detailed optimization, beyond the scope explored in this manuscript, is required for this small scale application for enhanced performance characteristics.

Further improvement in the hydraulic optimization was attempted by adding curvature to the runner blades. The design investigated so far in this manuscript assumed a linear relationship between the leading and trailing edge blade angles as a function of meanline. Curvature was added to blade profiles at the hub and shroud spans of the blade and parameterized with a Bézier spline representation. All other optimization variables previously investigated were constant, and only the Bézier spline points were varied, thus yielding four variables to optimize. The optimization was conducted for the pump best efficiency design point. The hydraulic efficiency was increased by $0.2 \%$, but this greatly affected performance in turbine operation.

A more robust approach to the hydraulic optimization method would be to include more operational conditions in both pump and turbine directions. This would allow for an optimum 
solution to be found that not only would improve operation at the pump design best efficiency condition, but the design best efficiency turbine condition as well. It would also allow for a solution that improves both pumping and turbine efficiencies on average over the unit's designed operating conditions. The drawback to this approach is that approximately eighteen times more simulations would be necessary to characterize the effects of the optimization variables. This may be an unrealistic expectation unless simulation throughput is increased using high performance computing resources.

Pictured in FIG. 8 and FIG. 9 are contour plots of static pressure, axial, radial, and circumferential velocities in the stationary reference frame on a plane that passes through the runner mid-span. FIG. 8 are plots in the pump direction while FIG. 9 are for the turbine direction. The subplots labeled A, C, E, and G in both figures represent the preliminary design and $\mathrm{B}, \mathrm{D}, \mathrm{F}$, and $\mathrm{H}$ the optimized design. Comparing FIG. 8A and B, the static pressure field is very similar; however, a difference in the field at the blade leading and trailing edges is noticed. In FIG. 8C and D, an increase in positive radial velocity is depicted between the preliminary and optimized design. A slight increase can also be seen in the circumferential velocity between FIG. 8E and F. A noticeable difference in axial velocity between FIG. $8 \mathrm{G}$ and $\mathrm{H}$ is seen.

A change in the static pressure field in the turbine direction is seen in FIG. 9A and B. The static pressure is lower in the optimized design trailing edge region. The radial velocity depicted in FIG. 9C and D is also lower in this region on the blade's suction side. There is also an increase in circumferential velocity between the preliminary and optimized designs in FIG. 9E and F. There is also a significant difference in the axial velocity in FIG. 9G and H. The axial velocity is more positive near the leading edge of the blades, and more negative at the trailing edge. The noticeable changes in the flow field in turbine operation are mainly due to the change in wrap 
angle of the blades between the preliminary and optimized designs. The increase in wrap angle was beneficial in pump operation, but adversely affected the flow field in turbine operation. 

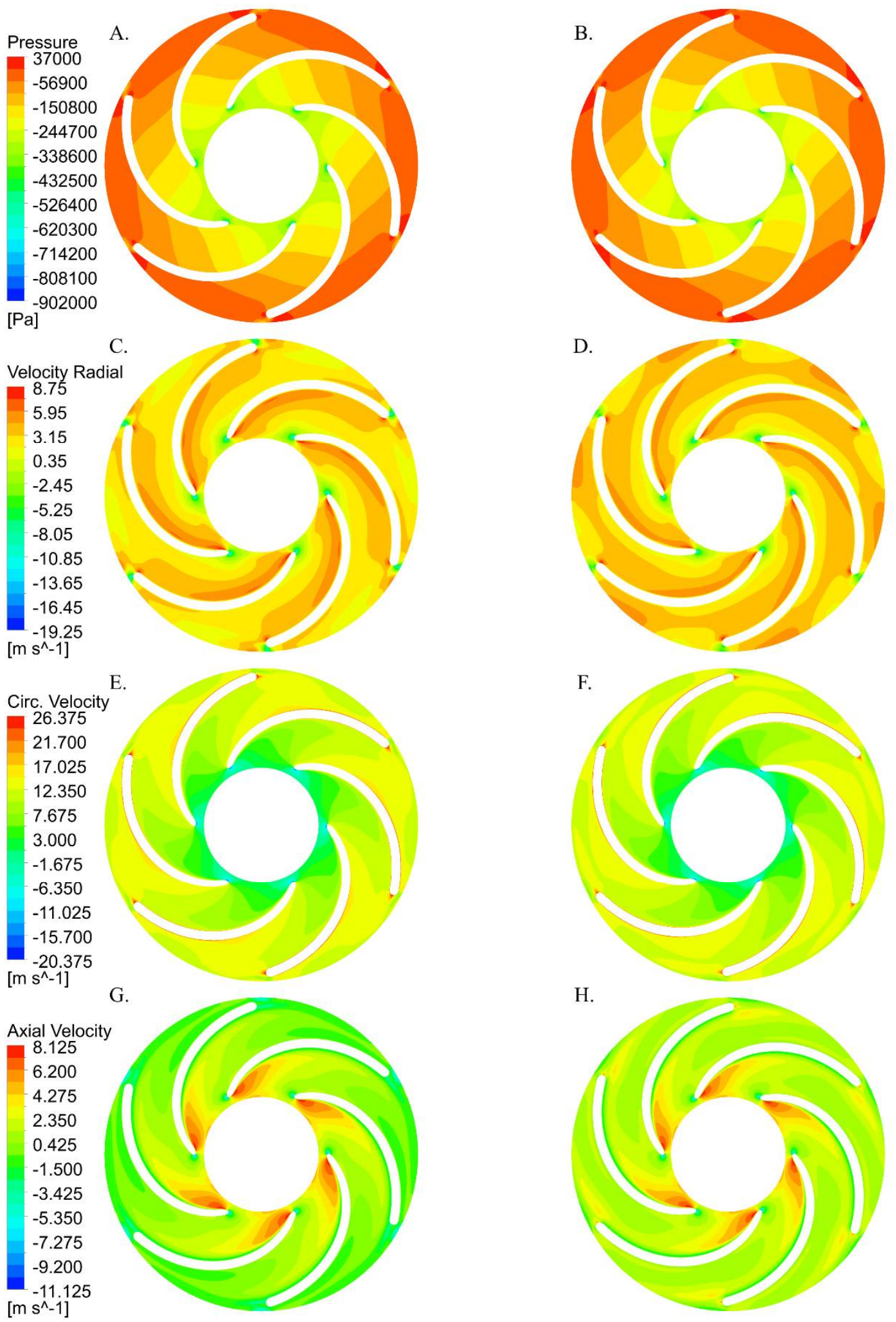

FIG. 8. Pressure and Velocity Components at the Mid-span of the Runner for A, C, E, and G the Preliminary Design and B, D, F, and H the Optimized Design in Pump Operation 

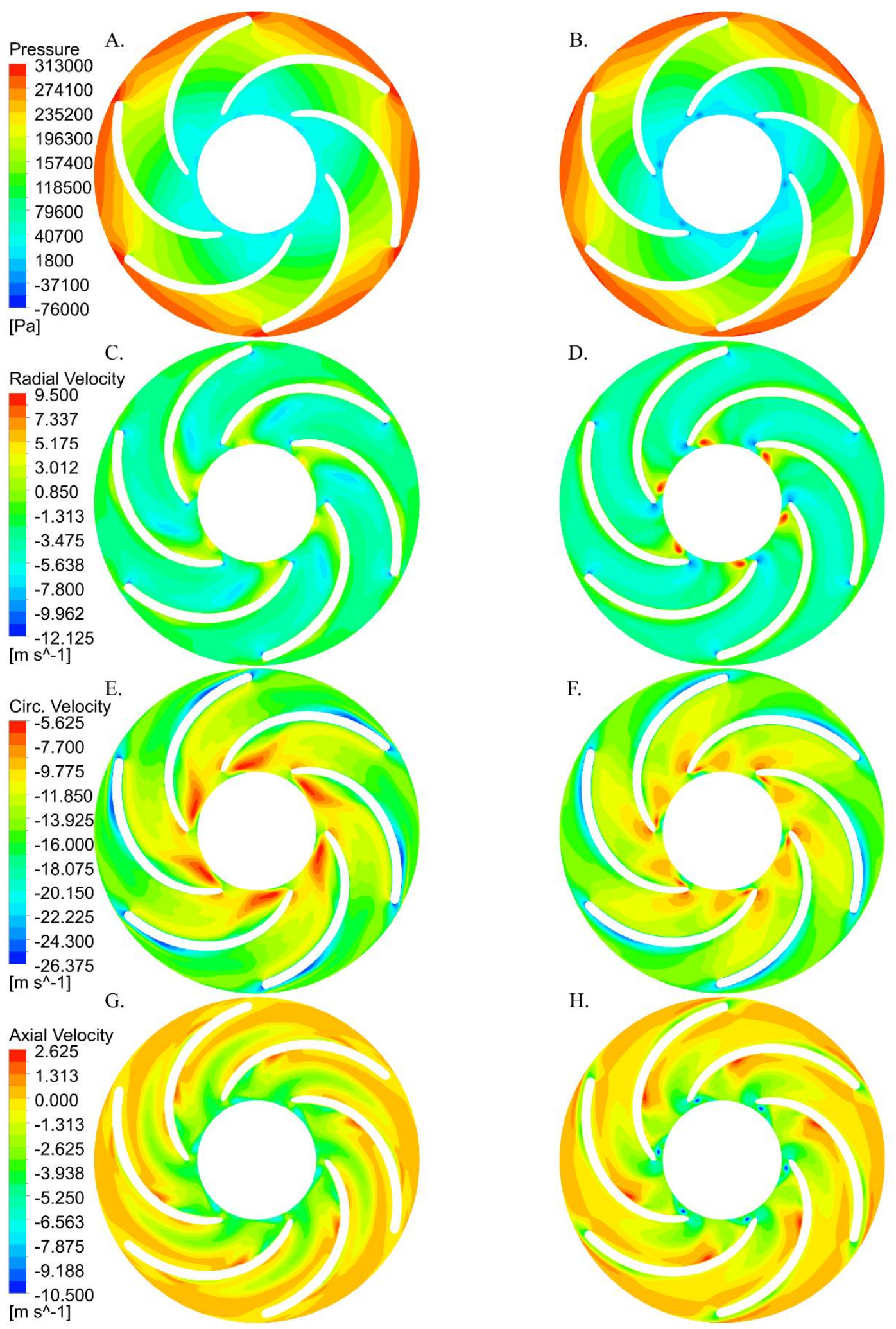

FIG. 9. Pressure and Velocity Components at the Mid-span of the Runner for A, C, E, and G the Preliminary Design and B, D, F, and H the Optimized Design in Turbine Operation 


\section{CONCLUSIONS}

The presented work lays the foundation for an exciting extension to current energy storage practices. The inclusion of more renewable energy sources into power grids is inevitable, and small energy storage solutions will play an increasing role in this endeavor. Small, modular pumped-storage solutions are an excellent complement to these renewable energy sources and can provide benefits besides energy storage such as wastewater treatment, allowing these systems to be an attractive infrastructure investment. Ma et al. [5] showed that a pumped-storage system at the studied scale in this manuscript would be a cost competitive solution for a renewable energy micro-grid.

A preliminary runner design was developed based on existing literature $[26,27,28]$. A mesh discretization study was performed, and found that convergence was reached around a nine million cell mesh. The runner's performance was characterized in both the pump and turbine directions for its designed operating conditions for both the preliminary design and an optimized design.

Response surface optimization was successfully applied in the hydraulic design of pumpturbine runners. The presented work managed to improve pump hydraulic efficiency by $1.06 \%$ at its best efficiency point. In future optimization studies, both the hydraulic design in pump and turbine directions should be considered during the optimization to ensure a more optimum solution is found in both pump and turbine operation. This work only considered the designed best efficiency point in pump direction during the optimization routine, and turbine hydraulic efficiency was slightly affected by $0.70 \%$ at its best efficiency point. The round-trip total efficiency of the system is estimated to be $78.7 \%$, which is comparable to current large-scale pumped storage schemes. Improvement in performance characteristics between the preliminary 
and optimized design was minimal for the quantity of power the pump-turbine operates with; a more detailed optimization analysis is needed for a more fruitful benefit from optimization.

The runner flow field had noticeable differences between the optimized and preliminary designs in both pump and turbine directions. An increase in static pressure at the leading edge, and general increases in velocity were observed between the preliminary and optimized designs in pump operation. A decrease in static pressure and radial velocity, and increase in circumferential velocity were observed at the trailing edge in turbine operation. There was also an increase in positive axial velocity at the leading edge in turbine operation.

In future studies, it will be beneficial to include more components in the hydraulic design such as guide vanes or a spiral case to better characterize the system. A structural and cavitation analysis would also help to further characterize the system. More design variables such as blade thickness distribution could also be accounted for in the optimization process. The aeration and wastewater treatment functionality must also be investigated further.

\section{ACKNOWLEDGMENT}

The authors would like to gratefully acknowledge that the information, data, or work presented herein was funded in part by the Office of Energy Efficiency and Renewable Energy (EERE), U.S. Department of Energy, under Award Number DE-EE0002668 and the Hydro Research Foundation. 


\section{DISCLAIMER}

The information, data or work presented herein was funded in part by an agency of the United States Government. Neither the United States Government nor any agency thereof, nor any of their employees, makes and warranty, express or implied, or assumes and legal liability or responsibility for the accuracy, completeness, or usefulness of any information, apparatus, product, or process disclosed, or represents that its use would not infringe privately owned rights. Reference herein to any specific commercial product, process, or service by trade name, trademark, manufacturer, or otherwise does not necessarily constitute or imply its endorsement, recommendation or favoring by the United States Government or any agency thereof. The views and opinions of authors expressed herein do not necessarily state or reflect those of the United States Government or any agency thereof. 


\begin{tabular}{|c|c|c|c|}
\hline \multicolumn{4}{|c|}{ NOMENCLATURE } \\
\hline \multicolumn{2}{|c|}{ Full Scripts } & $\varepsilon$ & permutation symbol \\
\hline $\mathrm{b}$ & length between hub and shroud & $\eta$ & efficiency / specific speed \\
\hline $\mathrm{C}$ & coefficient / velocity & $\mu$ & dynamic viscosity, Pa-s \\
\hline $\mathrm{D}$ & diameter, $\mathrm{m}$ & $v$ & kinematic viscosity, $\mathrm{m}^{2} / \mathrm{s}$ \\
\hline $\mathrm{F}$ & blending function & $\rho$ & density, $\mathrm{kg} / \mathrm{m}^{3}$ \\
\hline g & local gravitational constant & $\tau$ & torque, $\mathrm{N}-\mathrm{m}$ \\
\hline $\mathrm{H}$ & Head, $\mathrm{m}$ & $\omega$ & angular velocity, $\mathrm{rad} / \mathrm{s}$ \\
\hline $\mathrm{k}$ & turbulent kinetic energy, $\mathrm{J} / \mathrm{kg}$ & $\omega$ & specific dissipation rate, $\mathrm{rad} / \mathrm{s}$ \\
\hline $\mathrm{K}$ & empirical coefficient & & \\
\hline $\mathrm{L}$ & length scale, $\mathrm{m}$ & \multicolumn{2}{|c|}{ Superscript } \\
\hline $\mathrm{N}$ & rotation $\mathrm{rate}, \mathrm{rad} / \mathrm{s}$ & $*$ & denotes a closure coefficient \\
\hline $\mathrm{P}$ & power, W & ‘ & denotes the blade angle \\
\hline Q & volumetric flow rate, $\mathrm{m}^{3} / \mathrm{s}$ & & \\
\hline $\mathrm{S}$ & mean rate-of-strain tensor, $\mathrm{rad} / \mathrm{s}$ & \multicolumn{2}{|c|}{ Subscripts } \\
\hline S & blade thickness, m & 11 & Unit head and unit diameter \\
\hline $\mathrm{t}$ & time, $\mathrm{s}$ & $\mathrm{a}$ & absolute \\
\hline $\mathrm{t}$ & thickness, m & $\mathrm{cm}$ & meridional velocity coefficient \\
\hline $\mathrm{U}$ & velocity, $\mathrm{m} / \mathrm{s}$ & $\mathrm{H}$ & hydraulic \\
\hline Z & number of blades & $\begin{array}{l}\mathrm{k}, \omega, \omega 2 \\
\mathrm{i}, \mathrm{j}, \mathrm{k}, \mathrm{l}, \mathrm{s}, \mathrm{t}\end{array}$ & $\begin{array}{l}\text { denotes different colure coefficients } \\
\text { tensor indices }\end{array}$ \\
\hline Greeks & mbols & $\mathrm{r}$ & relative \\
\hline$\alpha, \beta, \sigma$ & closure coefficients & ref & reference \\
\hline & 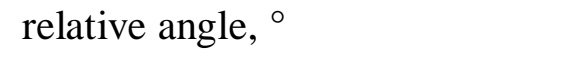 & $\mathrm{sp}$ & pump specific speed \\
\hline$\Delta$ & change in variable & $\mathrm{T}$ & turbulent / total \\
\hline
\end{tabular}

\section{REFERENCES}

[1] H. Ibrahim, A. Ilinca and J. Perron, "Energy storage systems- Characteristics and comparisons," Renewable and Sustainable Energy Reviews, vol. 12, pp. 1221-1250, 2008.

[2] R. Zogg, L. Tyson, D. Ofer and J. Brodrick, "Distributed Energy Storage," ASHRAE Journal, vol. 49, no. 5, pp. 90-94, 2007.

[3] C.-J. Yang and R. B. Jackson, "Opportunities and barriers to pumped-hydro energy storage in the United States," Renewable and Sustainable Energy Reviews, vol. 15, pp. 839-844, 2011.

[4] N. Sivakumar, D. Das and N. P. Padhy, "Economic analysis of Indian pumped storage schemes," Energy Conversion and Management, vol. 88, pp. 168-176, 2014.

[5] T. Ma, H. Yang and L. Lu, "Feasibility study and economic analysis of pumped hydro storage and battery storage for a renewable energy powered island," Energy Conversion and Management, vol. 79, pp. 387-397, 2014. 
[6] J. S. Anagnostopoulos and D. E. Papantonis, "Pumping station design for a pumped-storage wind-hydro power plant," Energy Conversion and Management, vol. 48, pp. 3009-3017, 2007.

[7] F. Wang and J. Jiang, "A novel static frequency converter based on multilevel cascaded Hbridge used for the startup of synchronous motor in pumped-storage power station," Energy Conversion and Management, vol. 52, pp. 2085-2091, 2011.

[8] N. Sivakumar, D. Das and N. P. Padhy, "Variable speed operation of reversible pumpturbines at Kadamparai pumped storage plant - A case study," Energy Conversion and Management, vol. 78, pp. 96-104, 2014.

[9] R. S. Koebbe, "Benefits and applications of modular hydroelectric pumped storage," in Waterpower '91: A New View of Hydro Resources, Denver, Colorado, 1991.

[10] J. E. Eastwood, "Modular design expands applications of pumped storage," Paper (American Society of Mechanical Engineers), 1990.

[11] R. S. Koebbe, "Strategic, operating and economic benefits of modular pumped storage," in Proceedings of the International Conference on Hydropower, Nashville, 1993.

[12] H. Nautiyal, Varun, A. Kumar and S. Yadav, "Experimental Investigation of Centrifugal Pump Working as Turbine for Small Hydropower Systems," Energy Science and Technology, vol. 1, no. 1, pp. 79-86, 2011.

[13] J. Ledolter and R. V. Hogg, Applied Statistics for Engineers and Physical Scientists, Upper Saddle River, New Jersey: Pearson Prentice Hall, 2010.

[14] G. Venter, "Review of Optimization Techniques," in Encyclopedia of Aerospace Engineering, John Wiley \& Sons, Ltd., 2010, pp. 1-12.

[15] G. E. P. Box and K. B. Wilson, "On the experimental attainment of optimum conditions," Journal of the Royal Statistical Society, Series B (methodological), vol. 13, pp. 1-45, 1951.

[16] C. M. Jang and Y. M. Kim, "Optimization of a stator blade using responce surface method in a single-stage transonic axial compressor," in Proc. IMechE Part A: J. Power and Energy, 2005.

[17] S. Kim, J. Park, K. Ahn and J. Baek, "Numerical investigation and validation of the optimization of a centrafugal compressor using a responce surface method," in Proc. IMechE Part A: J. Power and Energy, 2010.

[18] Y. Li, L. Li, T. Zhao and J. Li, "Aerodynamic optimisation of a low-pressure multistage turbine using the responce-surface method," Journal of Mechanical Science and Technology, vol. 27, no. 8, pp. 2537-2546, 2013. 
[19] F. Rubechini, A. Schneider, A. Arnone, S. Cecchi and F. Malavasi, "A redesign strategy to improve the efficiency of a 17-stage steam turbine," ASME Journal of Turbomachinery, vol. 134, no. 3, 2012.

[20] C. Cravero and P. Macelloni, "Design optimization of a multistage axial turbine using a responce surface based strategy," in 2nd International Conference on Engineering Optimization, Lisbon, Portugal, 2010.

[21] W. C. Schleicher, J. Riglin, A. Oztekin and R. Klein, "Numerical optimization of a portable hydrokinetic turbine," in Marine Energy Technology Symposium, Seattle, Washington, 2014.

[22] W. C. Schleicher, H. Ma, J. Riglin, Z. Kraybill, W. Wei, R. Klein and A. Oztekin, "Characteristics of a micro-hydro turbine," Journal of Renewable and Sustainable Energy, vol. 6, pp. 1-13, 2014.

[23] W. C. Schleicher, J. Riglin, Z. Kraybill and A. Oztekin, "Design and simulation of a micro hydrokinetic turbine," in Proceedings of the 1st Marine Energy Technology Symposium, Washington, D. C., 2013.

[24] J. Riglin, W. C. Schleicher, Z. Kraybill, R. Klein and A. Oztekin, "Computational fluid dynamics and structural finite element analysis of a micro hydro turbine," in Proceedings of the ASME IMECE 2013, San Diego, California, 2013.

[25] W. C. Schleicher, J. D. Riglin and A. Oztekin, "Numerical characterization of a preliminary portable micro-hydrokinetic turbine rotor design," Renewable Energy, vol. 76, pp. 234-241, 2015.

[26] R. S. Stelzer and R. N. Walters, "Estimating Reversible Pump-Turbine Characteristics," National Technical Information Service, Springfield, Virginia, 1979.

[27] G. F. Round, Incompressible Flow Turbomachines: Design, Selection, Applications, and Theory, Gulf Professional Publishing: Oxford, 2004.

[28] S. Kaewnai and S. Wongwises, "Improvement of the Runner Design of Fancis Turbine using Computational Fluid Dynamics," American Journal of Engineering and Applied Sciences, vol. 4, no. 4, pp. 540-547, 2011.

[29] F. R. Menter, "Zonal Two Equation k- $\omega$ Turbulence Models for Aerodynamic Flows," AIAA Paper 93-2906.

[30] F. R. Menter, "Two-Equation Eddy-Viscosity Turbulence Models for Engineering Applications," AIAA Journal, vol. 32, no. 8, pp. 1598-1605, 1994. 
[31] J. Riglin, W. Schleicher and A. Oztekin, "Diffuser Optimization for a Micro-hydrokinetic Turbine," in International Mechanical Engineering Congress \& Exposition, Montreal, Canada, 2014.

\section{Hydraulic Design and Optimization of a Modular Pump-turbine Runner}

\section{W. Schleicher ${ }^{\text {b) }}$ and A. Oztekin}

Mechanical Engineering and Mechanics, P. C. Rossin School of Engineering and Applied Science, Lehigh University, Bethlehem, Pennsylvania 18015

- A modular pumped-storage scheme using elevated water storage towers is investigated

- The pumped-storage scheme also aides in the wastewater treatment process

- A preliminary hydraulic pump-turbine runner design is created based on existing literature

- The preliminary design is optimized using a response surface optimization methodology

- The performance and flow fields between preliminary and optimized designs are compared

\footnotetext{
b) Corresponding Author:. Electronic mail: wcs211@ @ehigh.edu Phone: +1724-584-0143
} 